\title{
TESTBED FOR IMPLEMENTATION OF ADVANCED IT
}

\author{
Atanas NACHEV
} owadays the quality and quantity of information resources are becoming
important indicators of defense potential. Success in any type of military confrontation depends to a considerable extent on the results of the information confrontation between the opponents. When the combat potentials are comparable, reaching supremacy over the enemy is possible only through ensuring superiority in C2 systems, ${ }^{1}$ which these days cannot be realized without using the latest achievements in the field of information technologies. The development of $\mathrm{C} 2$ systems is therefore considered to be the fastest and economically justified way to enhance the combat potential of the defense forces.

For defense purposes, advanced information technologies are materialized in different in purpose, range and realized functions automated management systems (AMS) and automated information systems. At operational and tactical levels, automation management systems may be classified according to purpose, structure and tasks. Each system of this kind is designed in modules, unified according to the specific functions it has to fulfill. The practical realization of such systems is accompanied by a number of difficulties, defined by factors such as diversity of troop units, distribution in space, expedition of the management activities and work in extreme conditions such as fire or radio-electronic influence by the enemy. The management automation of the troops' everyday activities is based on advanced information technologies. The characteristics in this case are as follows:

- Establishing favorable conditions to make general decisions by using common customer resources;

- Data processing and storing in the most convenient for the system location while meeting the necessary requirements for information security;

- Utilizing existing standards as the basis for integration within the system's framework and at an intersystem level; 
- Modular design;

- Maximum use of existing equipment, even if it is not a subject of upgrading.

The systematic architectures being built are multilevel with vertical and horizontal branches. Automated weapon control systems, the means for technical reconnaissance and radio-electronic warfare make up a special class of AMS with important problems to solve and a specific way of building and functioning, as a rule, in extreme conditions.

Activities directly connected with combat, operational and mobilization training of troops, as well as those potentially enhancing the effectiveness of field control systems, of armament and combat equipment have priority in automation. The role of the automated control systems and automated information systems used in staff work, especially for implementation of critical procedures, has increased. A promising approach to increase the stability and effectiveness of the control is the integration of resources for communication and control over troops and weapons.

The modern force management system is a complex multifunctional organism. Its effectiveness directly affects the successful fulfillment of the forces' functions. Nowadays, it is unthinkable to ensure effective management of troops and weapons without the overall utilization of the latest information technologies. That is why the "informatization" of the army should be approached as a priority task for the development of the armed forces. ${ }^{2}$ It should also be accompanied by a clearly expressed governmental support, an appropriate defense budget structure, an overall scientific provision with the increased role of the military research units in the defense organization, ${ }^{3}$ and a unified control over the processes of development and implementation of modern information technologies in the military area. Military research in this case should be viewed as an inseparable element of the general cycle of development, implementation and exploitation of resources and army management automation systems, carried out following a common plot and a unified management. This is a basic requirement for ensuring an overall and balanced automation of management processes. The experience so far has shown that any other approach leads to generation of irrational decisions, especially dangerous of which are those related to information security, ${ }^{4}$ unjustified expenditures, corruption of the idea of increasing the combat capabilities of the armed forces through implementing modern information technologies.

It should be underlined that in the last thirty years a great number of different automated systems for troops and weapons management have been developed and implemented in the Bulgarian armed forces. Experience has been gained in the area of automation management of specific army conditions. Well-qualified scientific specialists have been trained and traditions in this field have been established. The 
development of information technologies in the 90s has put forward new challenges to upgrade the defense management systems in order to achieve fast, stable, reliable, continuous and flexible management of the armed forces in everyday and combat command. This calls for:

- Computer equipment in all management bodies, as well as in strategic, operational and tactical units;

- Complex automation of the everyday management of the armed forces and processes of control over troops in combat;

- Provision of a developed communication system, which allows prompt and reliable transmission of information with the necessary quality.

All this imposes a new approach to implementing new information technologies in the armed forces management. The essence of this approach is in compliance with the following basic principles:

- All-round scientific support with maximum application of the available experience in the area;

- Profound research studies in military research units on specific defense problems, for which no ready-made decisions have been offered, and which, due to their specificity, have not been studied in civilian scientific organizations;

- Establishment of conditions for the research of proposed commercial-off-theshelf solutions and justification of their applicability in the military area;

- Wide application of simulation and physical modeling of structural and functional solutions related to automation systems created for defense purposes;

- Certifying equipment and software according to their applicability in the defense area;

- Timely and effective training of personnel.

Following these objectives, the leadership of the Bulgarian Ministry of Defense designed and implemented a technological scheme for the development and implementation of defense information technologies, which meets the requirements listed above. It has been materialized in a specially built Research and Demonstration Center (RDC) in the Institute for Advanced Defense Research (IADR) at the "Rakovski" Defense College in Sofia. The RDC has been established to perform the following functions:

- Research on advanced technological solutions in the field of information and communications technologies with regard to their application in the army; 
- Development and experimentation with software and technical applications designed specifically for the needs of the military;

- Testing of software-technical complexes and systems for management automation;

- Developing, experimenting and assessing concepts and means for information security;

- Physical modeling, simulation and study of advanced communications and information systems;

- Studying and certifying technical products for automation and systemic, technological and applied software;

- Training of personnel.

With its purpose, functions and establishment, the RDC has no equivalent in the country. Research is accompanied by the following specific features: conducting research on specific, essential for the defense of the country, scientific problems; creating necessary conditions to study proposed COTS technologies and solutions; creating functional models of systems under development; training personnel to use the systems being developed until they are in exploitation, using already built physical models of the systems.

For training purposes, a Center for Training on Network Technologies, including CISCO academy has been established in the IADR. The training process is carried out in close cooperation with the CIS and Interoperability Department in the "Rakovski" Defense College.

Scientific research in IADR on problems related to the development of communications technologies for the armed forces is carried out in accordance with the Plan for Scientific Activities at the MoD in close interaction with the Defense Planning Directorate and the Armaments Policy Directorate of the Ministry of Defense and the Communications and Information Systems Directorate of the General Staff of the Bulgarian armed forces. The research follows existing tendencies in organizing scientific studies in conditions of information warfare. ${ }^{5}$

The RDC is structured as follows:

- Research and demonstration hall with testing sites to study and assess commercial-off-the-shelf solutions and to build physical models and systems;

- Internet network which is an element of the general network environment of the "Rakovski" Defense College;

- Network Technologies Training Center;

- Laboratory for network technologies and information security; 
- Laboratory for electronic means and systems;

- Spectrometric laboratory;

A center for lectures, presentations and mass media conferences has also been established.

The activities carried out in the RDC are connected with the implementation of the several basic programs of the Ministry of Defense: the Membership Action Plan; upgrading the command, control, communications, surveillance, reconnaissance and information systems; decreasing military infrastructure; research and administration.

The establishment of the RDC has contributed to the achievement of the following:

- Conditions have been created to carry out research on advanced technological solutions in the area of information and communications technologies with regard to their application for the needs of the armed forces;

- Necessary technological conditions have been created for physical and simulation modeling of communications and information systems;

- Analyzing, assessing and implementing advanced network technologies for the needs of the defense;

- Certifying automation equipment, as well as systemic, technological and applied software;

- Conditions have been created to train specialists from the Bulgarian armed forces on the problems of advanced information technologies.

We believe that due to its purpose, realized functions and establishment, the RDC is unique and vitally important to the Ministry of Defense, General Staff of the Bulgarian armed forces and the state administration of the Republic of Bulgaria. 


\section{Notes:}

1 Velizar Shalamanov and Todor Tagarev, Information Aspects of Security (Sofia: ProCon, 1996).

2 Velizar Shalamanov, "Problems of security and maintenance of life cycle of information systems," Military Journal 58, 6 (1996): 83-90.

3 See Stefan Hadjitodorov and Todor Tagarev, "Scientific Research and Development in NATO," Military Journal 107, no. 4 (2000): 81-90; Matey Lalov, "Organization of advance defense research in conditions of information war," Military Journal 59, 4 (1997): 90-98.

4 Shalamanov and Tagarev, Information Aspects.

5 Lalov, "Organization of advance defense research."

ATANAS IVANOV NACHEV is an Associate professor at the "G.S. Rakovski" Defense Academy in Sofia, Bulgaria. Since January 2000 he is Head of "C4I systems" Section of the Institute for Advanced Defense Research. Prior to this appointment, Dr. Nachev served as Head of Communications and Information Systems Section of the Military Research Institute of the General Staff of the Bulgarian Armed Forces. He holds a M.Sc. (1979) and Ph.D. (1985) degrees in Computer Science. 